\title{
Commentary: APOE e4 Genotype Predicts Severe COVID-19 in the UK Biobank Community Cohort
}

\author{
Kyle Kasparian ${ }^{\dagger}$, David Graykowski ${ }^{\dagger}$ and Eiron Cudaback* \\ Department of Health Sciences, DePaul University, Chicago, IL, United States
}

Keywords: COVID-19, APOE and inflammation, APOE and COVID-19, APOE, APOE and SARS-CoV-2, APOE e4, APOE e4 and COVID-19, APOE e4 and inflammation

\section{A Commentary on}

APOE e4 Genotype Predicts Severe COVID-19 in the UK Biobank Community Cohort by Kuo, C. L., Pilling, L. C., Atkins, J. L., Masoli, J. A. H., Delgado, J., Kuchel, G. A., et al. (2020). medRxiv 2020.2005.2007.20094409. doi: 10.1101/2020.05.07.20094409

OPEN ACCESS

Edited by:

Stefano Caserta,

University of Hull, United Kingdom

Reviewed by:

Mark R. Goldstein,

NCH Baker Hospital Downtown

(NCHMD), United States

David Melzer

University of Exeter, United Kingdom

*Correspondence:

Eiron Cudaback

ecudabac@depaul.edu

tThese authors have contributed equally to this work

Specialty section:

This article was submitted to Inflammation,

a section of the journal

Frontiers in Immunology

Received: 24 June 2020

Accepted: 17 July 2020

Published: 15 September 2020

Citation:

Kasparian K, Graykowski D and

Cudaback E (2020) Commentary:

APOE e4 Genotype Predicts Severe

COVID-19 in the UK Biobank

Community Cohort.

Front. Immunol. 11:1939.

doi: 10.3389/fimmu.2020.01939
On March 11th, 2020, the World Health Organization declared COVID-19 a pandemic. This respiratory disease results from infection by the novel SARS-CoV-2 virus, and commonly presents with flu-like symptoms, including cough, fever, and fatigue. More severe cases, generally defined by hospitalization, intubation, and/or mortality, can also exhibit dyspnea, lymphopenia, and hypoalbuminemia with concomitant increases in the proinflammatory cytokines interleukin 6 (IL-6), tumor necrosis factor alpha (TNF- $\alpha$ ), and interleukin 1 beta (IL-1ß) $(1,2)$. In addition, common COVID-19 comorbidities include dementia, heart disease, and hypertension (3-5). Clinical observations notwithstanding, surprisingly little is known about the molecular determinants that underlie this disease. Interestingly, the multiallelic apolipoprotein E gene $(A P O E)$, an important regulator of cholesterol homeostasis, has been similarly linked to Alzheimer's disease and cardiovascular disease (6-8).

Three common $A P O E$ alleles exist in the population, $\varepsilon 2, \varepsilon 3$, and $\varepsilon 4$. To investigate the relative contribution of $A P O E$ genotype to the risk for developing severe COVID-19, Kuo et al. analyzed case data from the UK Biobank (UKB) cohort (9), a study of 322,948 subjects of European ancestry, with a mean age of 68 years. Subjects were sorted by APOE genotype, and the number of positive COVID-19 tests between March 16th and April 26th, 2020 was recorded for each group. The authors found that individuals homozygous for $A P O E \varepsilon 4$ were more likely to test positive for COVID-19, and thus severe disease, compared the group homozygous for APOE $\varepsilon 3$ (9). Given the urgency for genetic determinants associated with COVID-19 severity, Kuo et al. continued their investigation with the addition of more test results and mortality data (10). The study confirmed their initial findings, additionally reaching genome-wide significance for the association of $A P O E \& 4 \varepsilon 4$ genotype with COVID-19 test positivity. The initial analysis characterized positive cases as severe COVID-19 cases given positive tests were registered from March 16th to April 26th, 2020, a window of time in which testing was largely restricted to hospitalized patients. Importantly, however, the less restrictive temporal parameters established in the follow-up study significantly undermine this premise. Nevertheless, the mortality data presented (calculated by quantifying deaths after confirmed positive) suggests increased disease severity in these subjects (10). Moreover, they reported that $A P O E \varepsilon 4 \varepsilon 4$ genotype was associated with a 4 -fold increase in mortality after testing positive relative to $A P O E \varepsilon 3 \varepsilon 3$ individuals. These data suggest that the APOE $\varepsilon 4 \varepsilon 4$ genotype represents a significant risk for the development of severe COVID-19, as well as death following infection. Interestingly, $A P O E \varepsilon 3 \varepsilon 4$ COVID-19 positive subjects did not exhibit 
a significant difference in mortality compared to $A P O E \varepsilon 3 \varepsilon 3$ positive subjects, and only a slight increase in positivity. This observation implies the absence of any gene dosage effects, underscoring the required inheritance of two $\varepsilon 4$ copies to acquire this genetic risk. Although these analyses identify APOE $\varepsilon 4 \varepsilon 4$ genotype as a potentially valuable genetic determinant for development of severe COVID-19, gaps remain in our current understanding of how specific mechanisms drive this association.

In addition to its critical function in lipid transport, $A P O E$ has also been shown to modulate important innate immune responses key to inflammation. For example, human subjects harboring $A P O E \& 4$ exhibit significantly higher plasma levels of proinflammatory cytokines (IL 6 and $\mathrm{TNF} \alpha$ ) following IV challenge with the bacterial endotoxin, lipopolysaccharide (LPS) (11). A hallmark of COVID-19 infection is aberrant inflammation resulting from a dysfunctional immune response. Given the data from Kuo et al. illustrating a strong association between severe COVID-19 cases and APOE $\varepsilon 4 \varepsilon 4$ genotype independent of the comorbidities, it is plausible that $A P O E$ modulates COVID-19 disease severity by regulating proinflammatory pathways in a genotype dependent manner.

Recently, there has been increased concern regarding the potential for chronic neurodegenerative effects following COVID-19 infection (12-14). APOE $\varepsilon 4$ has also been shown to exacerbate inflammation in the CNS following stressors that mimic infection in the periphery. Peripheral administration of LPS resulted in increased expression of the proinflammatory chemokine CCL3 in the brains of APOE TR mice in a genotype dependent manner $(\varepsilon 4>\varepsilon 3)$ (15). Furthermore, individuals carrying the APOE $\varepsilon 4$ allele exhibited accelerated breakdown of the blood brain barrier $(16,17)$. Thus, this not only creates concern for exacerbated inflammation in the periphery contributing to a cytokine storm during infection, yet also the potential for increased risk of long-term neurodegeneration in $A P O E \& 4$ infected patients.

The present studies come at a time when the identification of genetic factors influencing the development of COVID-19 are essential. Kuo and colleagues help to shed light on the association between $A P O E \& 4$ and severe COVID-19 infection, and establish

\section{REFERENCES}

1. Chen G, Wu D, Guo W, Cao Y, Huang D, Wang H, et al. Clinical and immunological features of severe and moderate coronavirus disease 2019. J Clin Invest. (2020) 130:2620-9. doi: 10.1172/JCI137244

2. Leemans JC, Cassel SL, Sutterwala FS. Sensing damage by the NLRP3 inflammasome. Immunol Rev. (2011) 243:152-62. doi: 10.1111/j.1600-065X.2011.01043.X

3. Schiffrin EL, Flack JM, Ito S, Muntner P, Webb RC. Hypertension and COVID-19. Am J Hypertens. (2020) 33:373-4. doi: 10.1093/ajh/hpaa057

4. Xie J, Tong Z, Guan X, Du B, Qiu H. Clinical characteristics of patients who died of coronavirus disease 2019 in China. JAMA Netw Open. (2020) 3:e205619. doi: 10.1001/jamanetworkopen.2020.5619

5. Docherty AB, Harrison EM, Green CA, Hardwick HE, Pius R, Norman L, et al. Features of 16,749 hospitalised UK patients with COVID-19 using the ISARIC WHO clinical characterisation protocol. medRxiv. (2020) 2020.2004.2023.20076042. doi: 10.1101/2020.04.23.20076042 a starting point from which to initiate empirical and replicable studies aimed at investigating the molecular nature of such genetic risks. Indeed, these findings encourage comprehensive interpretations of population-specific susceptibilities to COVID19 like those observed among African Americans (18), and the role that variation in $A P O E$ allele frequency may play (19). Their work also provides an important foundation from which to explore the biological mechanisms that underlie these associations. Given the compelling evidence linking aberrant inflammation to severe COVID-19 (20), and the association of $A P O E \& 4$ with exacerbated inflammation, future studies should aim to determine if $A P O E \varepsilon 4$ is associated with increased inflammatory responses in the periphery following COVID-19 infection. This could easily be demonstrated by investigating plasma cytokine levels, as well as other immunological markers. Additionally, COVID-19 infection poses as a threat to the CNS given neuroinflammation is a universal characteristic across an array of neurodegenerative diseases. Therefore, longitudinal effects of COVID-19 infection in APOE $\varepsilon 4$ carriers, which exhibit exacerbated neuroinflammatory responses (21), may lead to exacerbated risk for developing these aliments. Taken together, future studies are necessary to elucidate an association between $A P O E \& 4$, inflammation, and COVID-19 infection, and characterize the biological mechanisms underlying this link. These studies should be strongly considered by the research community, because if an association exists, then millions of $A P O E \& 4$ carriers worldwide must take additional precautions to prevent developing a devastating and life-threatening disease.

\section{AUTHOR CONTRIBUTIONS}

KK, DG, and EC conceived of and wrote the manuscript. All authors contributed to the article and approved the submitted version.

\section{ACKNOWLEDGMENTS}

We thank DePaul University for supporting this project.
6. Curtiss LK. ApoE in Atherosclerosis. Arterioscler Thromb Vasc Biol. (2000) 20:1852-3. doi: 10.1161/01.ATV.20.8.1852

7. Yamazaki Y, Zhao N, Caulfield TR, Liu C-C, Bu G. Apolipoprotein E and Alzheimer disease: pathobiology and targeting strategies. Nat Rev Neurol. (2019) 15:501-18. doi: 10.1038/s41582-019-0228-7

8. Iadecola C, Yaffe K, Biller J, Bratzke LC, Faraci FM, Gorelick PB, et al. Impact of hypertension on cognitive function: a scientific statement from the American Heart Association. Hypertension. (2016) 68:e67-94. doi: 10.1161/HYP.0000000000000053

9. Kuo C-L, Pilling LC, Atkins JL, Masoli J, Delgado J, Kuchel G, et al. APOE E4 genotype predicts severe COVID-19 in the UK Biobank community cohort. medRxiv. (2020) 2020.2005.2007.20094409. doi: 10.1101/2020.05.07.20094409

10. Kuo C-L, Pilling LC, Atkins JL, Masoli J, Delgado J, Kuchel G, et al. ApoEe4e4 genotype and mortality with COVID-19 in UK Biobank. medRxiv. (2020) 2020.2006.2019.20134908. doi: 10.1101/2020.06.19.20134908

11. Gale SC, Gao L, Mikacenic C, Coyle SM, Rafaels N, Murray Dudenkov $\mathrm{T}$, et al. APO 4 is associated with enhanced in vivo innate immune 
responses in human subjects. J Allergy Clin Immunol. (2014) 134:127-34. doi: 10.1016/j.jaci.2014.01.032

12. Heneka MT, Golenbock D, Latz E, Morgan D, Brown R. Immediate and long-term consequences of COVID-19 infections for the development of neurological disease. Alzheimers Res Ther. (2020) 12:69. doi: 10.1186/s13195-020-00640-3

13. Helms J, Kremer S, Merdji H, Clere-Jehl R, Schenck M, Kummerlen C, et al. Neurologic features in severe SARS-CoV-2 infection. N Engl J Med. (2020) 382:2268-70. doi: 10.1056/NEJMc2008597

14. Mao L, Jin H, Wang M, Hu Y, Chen S, He Q, et al. Neurologic manifestations of hospitalized patients with coronavirus disease 2019 in Wuhan, China. JAMA Neurol. (2020) 77:1-9. doi: 10.1001/jamaneurol.2020.1127

15. Cudaback E, Yang Y, Montine TJ, Keene CD. APOE genotype-dependent modulation of astrocyte chemokine CCL3 production. Glia. (2015) 63:51-65. doi: 10.1002/glia.22732

16. Montagne A, Nation DA, Sagare AP, Barisano G, Sweeney MD, Chakhoyan A, et al. APOE4 leads to blood-brain barrier dysfunction predicting cognitive decline. Nature. (2020) 581:71-6. doi: 10.1038/s41586-020-2247-3

17. Blanchard JW, Bula M, Davila-Velderrain J, Akay LA, Zhu L, Frank A, et al. Reconstruction of the human blood-brain barrier in vitro reveals a pathogenic mechanism of APOE4 in pericytes. Nat Med. (2020). doi: 10.1038/s41591-020-0886-4

18. Yancy CW. COVID-19 and African Americans. JAMA. (2020) 323:1891-2. doi: 10.1001/jama.2020.6548
19. Berg CN, Sinha N, Gluck MA. The effects of APOE and ABCA7 on cognitive function and Alzheimer's disease risk in african americans: a focused mini review. Front Hum Neurosci. (2019) 13:387. doi: 10.3389/fnhum.2019.0 0387

20. Felsenstein S, Herbert JA, McNamara PS, Hedrich CM. COVID-19: immunology and treatment options. Clin Immunol. (2020) 215:108448. doi: $10.1016 /$ j.clim.2020.108448

21. Tai LM, Ghura S, Koster KP, Liakaite V, Maienschein-Cline M, Kanabar P, et al. APOE-modulated A $\beta$-induced neuroinflammation in Alzheimer's disease: current landscape, novel data, and future perspective. J Neurochem. (2015) 133:465-88. doi: 10.1111/jnc.1 3072

Conflict of Interest: The authors declare that the research was conducted in the absence of any commercial or financial relationships that could be construed as a potential conflict of interest.

Copyright $\odot 2020$ Kasparian, Graykowski and Cudaback. This is an open-access article distributed under the terms of the Creative Commons Attribution License (CC $B Y)$. The use, distribution or reproduction in other forums is permitted, provided the original author(s) and the copyright owner(s) are credited and that the original publication in this journal is cited, in accordance with accepted academic practice. No use, distribution or reproduction is permitted which does not comply with these terms. 